\title{
A Systematic Research on the Working Mechanism of Decategorization of Nouns in Mandarin Chinese*
}

\author{
Zhen Li \\ School of Foreign Languages, Zunyi Medical University, China
}

\begin{abstract}
Based on the previous research, this paper makes a systematic study of the working mechanism of decategorizaiton of nouns in Mandarin Chinese, employing the theories of metaphor and metonymy and the theory of duality of concept. The major findings are as follows: metonymy-metaphor interaction is the working mechanism in the decategorization of nouns in Mandarin Chinese, mainly metaphor from metonymy, with metonymy and metaphor, functioning at different stages of decategorization. At the initial stage, the basic working mechanism is WHOLE-PART METONYMY. By this mechanism, a certain meaning component in the type notion domain of a noun is highlighted through metonymical constituent perspectivization and subjectivization, expressing descriptive or assertive meaning related to the noun. At the final stage, the working mechanism is mainly categorical metaphor, of which the source domain is the token notion of a typical noun with concrete meaning while the target domain is the type notion with abstract sense intended to express in communication.
\end{abstract}

Index Terms - decategorization, nouns, metonymy, metaphor, interaction

\section{INTRODUCTION}

In communication, decategorized nouns are widely used in Mandarin Chinese. For example, 农村 (village) in 很农 村 (very village, very village-like) can express the assertive meanings such as poverty, backwardness, inconvenience of the rural area; 舌 (tongue) refers to the manner of action in 舌战群儒 (verbal fight with scholars ); 猫 (cat) denotes the action of staying just like a cat in 猫在家里 ( staying at home), etc.

The nouns mentioned above are decategorized, functioning as adjective, adverb and verb respectively in these examples. They have lost all the typical features of a noun: They cannot refer to a concrete thing, be used with a determiner or an adjective, or have its original distribution features, etc. At this point, the following question is asked: What is the working mechanism hidden behind the decategorization of nouns in Mandarin Chinese? The answer to this question is the objective of this study.

In this study, decategorized nouns in Mandarin Chinese, according to their functions and meanings, are mainly divided into three types, namely, adjectivalized nouns, adverbalized nouns and verbalized nouns. The working mechanism of these decategorized nouns will be studied from the perspective of the interaction of metonymy and metaphor.

The study tries to prove that decategorization of nouns is a process, which corresponds to the interaction of metaphor and metonymy, with metaphor and metonymy functioning at different stages of decategorization. It is hoped that the study can give satisfactory answers to the question asked above, providing a new approach to the study of decategorization of nouns in Mandarin Chinese.

\section{Literature REVIEW}

Some studies have been done both in China and in the West concerning the working mechanism of decategorization of nouns in Mandarin Chinese. However, there are still issues that need to be further studied.

Previous Studies on the Working Mechanism of Decategorization of Nouns in Mandarin Chinese

The notion of decategorization was first proposed by Hopper and Thompson (1984) and further studied by Heine, Claudi and Hunnemeyer (1991), Taylor (1995) etc. However, in the West, little attention is drawn to the study of decategorization of nouns. And no particular study was made concerning the working mechanism of decategorization of nouns, not to mention the working mechanism of decategorization of nouns in Mandarin Chinese.

Many studies on decategorization of nouns and its working mechanism in Mandarin Chinese have been made in China. The following are the representatives.

\footnotetext{
* This paper is supported by "Research Foundation on Humanities and Social Science of the Education Department of Guizhou Province (2018qn51)"
} 
Liu (2004, 2006) approached decategorized nouns in $N 1+N 2$ construction and stated that N(Noun)1 becomes decategorized and functions as an adjective expressing a descriptive sense. Liu $(2004 ; 2006)$ found that the working mechanism of $\mathrm{Nl}$ is mainly the metaphorical construal together with ICM.

Liu (2005) studied the working mechanism of linguistic decategorization. He showed that linguistic decategorization is characterized by the reference assertion interconversion, and the subjectification of meaning, which are realized by metaphorical mappings.

Liu and Cui (2005) probed the Adverb + Noun construction. They argued that nouns in this construction become decategorized and function as adjectives, expressing assertive meaning. In this process, semantic choices are made through metonymical perspectivization based on the type notion of the noun.

Liu (2005) discussed the tautological construction, $N P+$ (will) $B E+N P$. He stated that the two NPs (noun phrases) are decategorized to some degree semantically and functionally. As for the working mechanism, he focused on categorical metaphor though metonymy was also mentioned.

Peng and Liu (2007) studied $N$-to-V conversion. They found that the working mechanism of this conversion should be explained from the perspective of concept transformation and creativity in thought.

Pan (2010) explored the metonymy in the categorization of $N 1$ in $N 1+N 2$ compounds. He considered metonymical construal to be the prerequisite for the prominent metaphorical noun to enter the category of the substantive noun in the compounds to realize subcategorization.

\section{Issues to be Further Studied}

The scholars mentioned above have made great contributions to the study of the working mechansim of decategorized nouns in Mandarin Chinese. However, there are still issues which need to be further studied.

Firstly, too much attention is paid to the study of the metaphorical aspect; less attention is given to the metonymical aspect.

Secondly, the previous studies all acknowledged that the metonymy and metaphor can be the working mechanism of decategorization of nouns. However, the studies do not specify which kind of metonymy and metaphor can better explain this language phenomenon and in what way.

Thirdly, the relationship between metonymy and metaphor and its function is not specified in the decagegorization of nouns.

Based on the previous studies, a systematic study of decategorized nouns in Mandarin Chinese will be made and all the problems mentioned above can be solved accordingly.

\section{THEORETICAL FRAMEWORK}

Before approaching the working mechanism of decategorization of nouns in Mandarin Chinese, it is necessary to make clear some concepts and theories related to this study.

\section{Categorization and Decategorization}

Categorization and decategorization are indispensable and complementary to each other in human being's realization of the world and these two constitute the whole process of categorization.

\section{Categorization}

Entities in the world where we live are classified into different groups, to which proper names are given. This mental process of classification is commonly called categorization, and its products are the cognitive categories.

The development of categorization theory can be divided into three stages.

1. Classical theory This theory was proposed by Aristotle. According to Aristotle, categories are made of a limited number of necessary and sufficient features, there is a clear boundary between categories, and members of a category are the same in status.

However, the classical theory is far from satisfactory as it is only applicable to the categorization of objects with clear boundaries while it fails to group objects with vague boundaries.

2. Wittgenstein's family resemblance Through the study of the definition of game, Wittgenstein (1953) discovered that members of the category are related to each other through a set of similarities instead of the same properties. These overlapping similarities are defined as family resemblance by Wittgenstein.

3. Prototype theory Based on Brent Berlin and Paul Kay (1969), Rosch (1978) studied categorization from a cognitive perspective and proved that categories are formed around prototypes, which function as cognitive reference points. Members in a category are not equal in status. There are good members and bad members. Good examples are more typical and share the largest number of attributes with other members of the same category, while bad or marginal examples have only few attributes in common with members of the same category, but have several attributes of another category. And the boundary between categories is fuzzy.

\section{Decategorization}

According to Liu and Liu (2004), decategorization is a process in which a word moves to an intermediate category between the original category and the forthcoming new category. That is to say that, under certain conditions, members of a category gradually lose some of their specific categorical features while obtaining some of the features of another category. Before recategorization, those members are in an unstable, intermediate state. Please look at the following examples. 
(1) a. 森林里住着一只（狡猾的）大灰狼。

'A (cunning) timber wolf lives in this forest.'

b. 这片地区是狼的领地。

'This is the wolves' territory.'

c. 山东菄庄指狗为狼。

'The police in Zao Zhuang, Shan Dong province treated a dog as a wolf by mistake.'

d. 什么是狼性文化?

'What is the meaning of wolf culture?'

e. 他吃饭时总是狼吞虎咽的。

'He likes to wolf down the food when eating.'

In the above examples, 狼 in (1a) is a typical noun with a referent and can be modified by adjectives, determiners, and clauses. It occurs in the object place of a sentence. In (1b) and (1c) some of its typical features are lost. 狼 cannot refer to a real animal. And it is not used with an adjective or a determiner. However, 狼 in these two examples are still treated as nouns without any doubt. In (1d) and (1e), 狼 is not a typical noun any more, as it loses all the typical features of the category. It functions as an adjective and expresses a descriptive meaning.

These four examples reveal the process in which 狼 is decategorized. In such a process typical features of the noun are gradually lost while gaining certain features of an adjective or adverb.

Relationship Between Decategorization and Categorization

Categorization and decategorization are two close concepts like two sides of a coin. Categorization enables human beings to organize their experience from specific to general. On the contrary, decategorization goes from general to specific, which breaks the balance created by categorization.

Our realization of the world begins with categorization which enables us to classify the chaos into groups. Then some of the group members begin to lose some features of their category under certain conditions, and decategorization begins. Recategorization follows at the end of decategorization. Again, the whole process goes into a new cycle. Decategorization functions as a facilitator which pushes the process forward. The whole process can be described as follows: "Chaos-Categorization-Decategorization-Recategorization" (Liu \& Liu 2005, p. 30).

In a word, categorization and decategorization are indispensable and complementary to each other and they constitute the whole process of categorization.

\section{Metaphor and Metonymy}

From the cognitive point of view, both metaphor and metonymy are fundamental thinking patterns of human beings which are employed to conceptualize the world. They are different but closely related.

\section{Metaphor}

Metaphor can help us to understand a difficult concept by using the concept we are familiar with. It can be approached from two perspectives: conceptual and categorical.

\section{Conceptual metaphor}

Metaphor is defined as understanding one conceptual domain or cognitive domain in terms of another conceptual domain, based on the similarity between them. (Lakoff \& Johnson, 1980) The domain with which we are familiar and is used to understand another domain by drawing metaphorical expressions is called source domain. The unfamiliar conceptual domain that is understood by the source domain is called target domain. The relationship between source domain and target domain is a set of systematic correspondences, technically often referred to as mappings.

\section{Categorical metaphor}

Heine, Claudi and Huennemyer (1991) claimed that the conceptual metaphors proposed by Lakoff such as HAPPY IS UP, SAD IS DOWN, MORE IS UP, LESS IS DOWN, all concern the expression of characteristics or states by means of spatial concepts. They found that these conceptual metaphors are actually conceptual metaphor clusters which can be defined as a more general categorical metaphor with space being the source domain and characteristics being the target domain. They also claimed that based on the relative degree of metaphorical abstraction, from left to right the metaphor mapping is characterized by the following direction: "person $>$ thing $>$ activity $>$ space $>$ time $>$ characteristics" (Heine, Claudi \& Huennemyer, 1991, p. 48) .

In categorical metaphor, those on the left directions are concrete entities such as person, thing or activity and all these can be the source domains. And those on the right are abstract notions such as space, time and characteristics. Thus they can be the target domain which is intended to convey in communication.

Metonymy

Metonymy, in the cognitive literature, is defined as a cognitive process in which the vehicle provides mental access to the target in the same domain. Metonymy in the cognitive literature is taken as Idealized Cognitive Models (ICMs) by Lakoff (1987), conceptual mappings by Radden and Kovecses (1999), domain highlighting by Croft (1993), combinations of mappings and highlighting by Ruiz de Mendoza (2000), scenarios by Panther and Thornburg (1998) and more generally as reference-point activation by Langacker (1993) and Barcelona (2000).

Radden \& Kovecses (1999) classify metonymy into two types: (1) the relationship between part and whole, and (2) the relationship between parts in the whole. 


\section{Part-Whole metonymy}

According to Radden and Kovecses (1999), the Part-Whole metonymy can be further divided into six types.

1. THING-PART METONYMY A thing can be treated as an integrated whole which is made up of different parts. This kind of metonymy includes two patterns which are the whole for the part and the part for the whole.

2. SCALE METONYMY The whole scale of an entity or the upper end of a scale can be used to refer to the scale as a whole.

3. CONSTITUTION METONYMY The material of an entity can be used to refer to the entity or the entity to refer to its material.

4. DOMAIN-MEMBER METONYMY The whole domain can be used to refer to its members and the salient member of a domain to the whole domain.

5. EVENT METONYMY The event includes many subevents which happen continually or simultaneously. In the event metonymy, the whole event can refer to its subevents or certain event can denote the whole event.

6. DOMAIN-FEATURE METONYMY The meaning of an entity is the same as its cognitive domain which can be defined with its features. On the one hand, the domain can be used to denote certain features of this entity. On the other hand, the main features of a domain can be used to refer to a domain.

Part-Part metonymy

Part-Part metonymy can be further divided into seven subtypes.

1. CAUSE-EFFECT METONYMY In communication, the effect and cause can be used to replace each other.

2. INSTRUMENT METONYMY Naturally, the instrument is also associated with its user and can be substituted for each other.

3. PRODUCTION METONYMY The production is closely related to its producer, and thus they are often used to replace each other.

4. POSSESSION METONYMY The possession and possessor can be used to replace each other.

5. CONTROL METONYMY In this kind of metonymy, the controller and the controlled can be used for each other.

6. LOCATION METONYMY The place is often associated with its history, unique folk customs, natural conditions and its inhabitants. Thus the place can be used to refer to the related things about this place.

7. CONTAINMENT METONYMY The container and its content are close to each other. They can be used to refer to each other.

The theory proposed by Radden \& Kovecses (1999) is more inclusive than others. It can give some hints to the study of the decategorization of nouns in Mandarin Chinese. Thus, it is adopted in this paper.

\section{Interactions Between Metonymy and Metaphor}

Being two fundamental thinking patterns, metonymy and metaphor have a close relationship with each other. Some researches show that metonymy seems to be more fundamental than metaphor and the former serves as the basis and motivation for the latter.

Taylor (1995) points out that metonymy is one of the most fundamental process of meaning extension, perhaps even more basic than metaphor.

Radden and Kovecses (1999), after studying the internal relationship within the semantic triangle, propose that language is metonymical in nature.

Goossens (1995) insists that the relationship between metonymy and metaphor is interactive and intricate rather than static. He proposed the term metaphtonymy to show the close interaction between these two thinking patterns.

Barcelona (2000) argues that there are two kinds of interactions between metonymy and metaphor. One is metonymical conceptual motivation of metaphor, the other is metaphorical conceptual of metonymy. He insists on the idea that metaphor is motivated from metonymy at the conceptual level, whereas such metonymy is close to experimental basis of the metaphor and vice versa. And Barcelona (2000) even comes up with a radical hypothesis that every metaphor is motivated by conceptual metonymy.

Goossens (1995) divides the interaction between metonymy and metaphor into four types based on body part corpus which are metaphor from metonymy, metonymy within metaphor, metaphor within metonymy and demetonymisation in a metaphorical context, of which the first two are most commonly used.

1. Metaphor from metonymy This kind of metaphor can be obtained from its metonymical origin based on the relevance between the linguistic action and non-linguistic action reading. This can be illustrated in Figure 1.

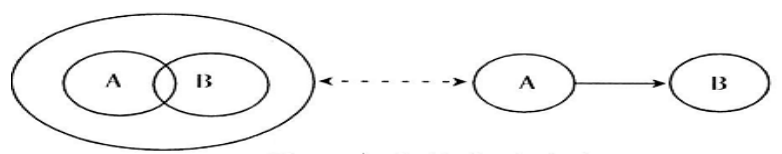

Figure 1: Metaphor from metonymy (Goossens, Pauwels, Rudzka-Ostyn, Simon-Vandenbergen, \& Vanparys, 1995, p. 362)

2. Metonymy within metaphor In this pattern, the metonymy is built in the metaphor. In most cases, the metonymy only functions in the target domain. The typical example is that a metonymically used entity is embedded in a metaphorical expression. This metonymy includes the shared element X in domains A \& B as illustrated in the Figure 2. 


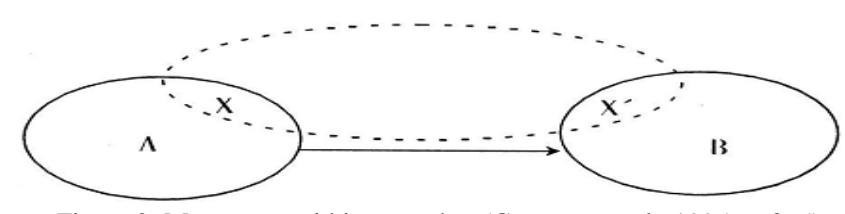

Figure 2: Metonymy within metaphor (Goossens et al., 1995, p. 365)

\section{Theory of Duality of Concept}

Jackendoff (1983) proposes the theory of duality of concept in order to study the relationship between cognition and semantics. This theory will be introduced in detail in the fifth part for the convenience of discussion.

\section{DeCATEgorization of Nouns in MANDARIN ChINESE}

In our daily communication, nouns show a tendency of functioning as other categories such as, adjectives, adverbs or verbs, etc. They lose some features that typical nouns possess, such as being modified by determiners, adjectives or clauses, having anaphors in a context, introducing a participant in a sentence, etc. This is called decategorization of nouns. In such a process, three tendencies are identified in Mandarin Chinese: adjectivalization, adverbalization and verbalization.

\section{Adjectivalization of Nouns}

Under certain conditions, while losing some typical features, some nouns in Mandarin Chinese gain certain features of adjectives. Those decategorized nouns seem to be located between the category of nouns and adjectives and play functions of adjectives. They frequently occur in the following constructions: $N 1+N 2, N+$ (will) be $+N$, Degree Adverb + Noun, and $X+b i($ 比 $)+N+$ hai $($ 还 $)+N$.

\section{$N 1+N 2$ Construction}

In $N 1+N 2$ construction, $\mathrm{N} 1$ is decategorized, functioning as an adjective. It is used to describe certain features of N2. For example,
(2) a. 北京烤鸭 (Beijing Roast Duck)
c. 铁娘子 (iron lady)
b. 土豪金 (luxury gold color)
e. 石登 (stone seat)
d. 斑马线 (zebra crossing)
g.蜗居 (snail dwelling)
f. 水桶要 (bucket waist)
i. 瓜葛 (relationship)
h. 银发 (white hair)
1. 草包 (useless man)
j. 宠物狗 (pet dog)
k. 抹布女(rag women)

$N 1+N 2$ construction in Mandarin Chinese falls into different types. Based on Liu (2006), we group them into three types. They are generalizing abstraction, isolating abstraction, and blending types.

In the generalizing abstraction type, $N 1$ undergoes generalizing abstraction which means $N 1$ loses their semantic specificities and becomes more general. More specifically, $N 1$ functions as a modifier denoting certain distinguishable features of $N 2$ and has no concrete referent in the world. In(2a), 北京 suggests the place of production; in (2e), 石 denotes the material; in (2j), 宠物 implies the function. However, in these examples, $N 1$ just experienced minor degree of decategorization. Some of them can have its plural form and be used with adjectives and determiners. For example, (一条)(听话的)宠物狗 (a [tame] pet dog).

In the second type, $N 1$ undergoes isolating abstraction. Only one particular part of the meaning of $N 1$ is highlighted while others are ignored. The meaning of the construction is formed by mapping of the highlighted meaning component of $N 1$ to $N 2$. (2h), (2d), (2c) (2b) and (2f) belong to this type.

In blending type, meaning of the newly formed phrase has nothing to do with meaning of $N 1$ and $N 2$. These lexicalized phrases whose novelty and creativity become lower due to the high frequency of use in language and their meanings become fixed in daily use. (2g) and (2l) are members of this type. In (2g), 瓜 and 暮 both refer to a kind of plant with twisted vines intertwined together, revealing the complicated relationship among people.

From the above analysis, the differences of the three types can be easily found. Generalizing abstraction type is less typical than the isolating abstraction type since the former can be used with determiners and adjectives. Meanwhile, most examples of the third type have a fixed meaning after the process of lexicalization. Thus the second type, isolating abstraction is the main target of our study.

Degree Adverb + Noun Construction

In traditional grammar, adverbs can only be used as modifiers of adjectives or verbs, but not of nouns in both Chinese and English. But in recent years, grammatically nonstandard language, such as, Degree Adverb + Noun construction has gained its popularity especially in novels, newspapers, and the internet due to its powerful expressive ability and unique pragmatic effect. For example,

(3) 他们俩关系很铁。

'They have a close relationship.'

铁 becomes decategorized in this example. It loses the typical features of the noun category while gaining features of an adjective. It cannot refer to a concrete thing or be used with a determiner or an adjective. From the syntactic view, it 
is placed after the adverb and functions as an adjective, describing a certain feature of the noun. Here 很铁 means having a close relationship.

\section{$N+($ will $) b e+N$ Construction}

$N+$ (will) be $+N$ construction is referred to as tautology. This construction is widely used both in Chinese and English. What makes Chinese different from English is that Chinese must rely on some adverbs such as 到底, 终究, 就是, or 毕竟 to achieve the same tautological effect as English. For instance:

（4）有缺点的战土终竟是战士，完美的苍蝇也终竟不过是苍蝇。(《战士和苍蝇》)

'The fighter for all his blemishes is a fighter, while the most perfect flies are only flies.'

In (4), both 战士 and 苍蝇 are decategorized to some degree. They cannot refer to a real solider and fly. The first 战士 and 苍蝇 still have some of the typical features of a noun. For example, from the morpho-syntactic point of view, 战土 can be modified by an adjective 有缺点的 and 苍蝇 is modified by 完美的 respectively. From the semantic point of view, the second 战士 in this structure indicates some distinguishable features of a revolutionist, such as tough and indomitable. Meanwhile the second 苍蝇 is used to denote some bad characteristics of imperialists and reactionaries. Even though they are powerful at that time, they will be defeated by the revolutionists at last.

\section{$X+b i($ 比 $)+N+h a i($ 还 $)+N$ Construction}

In Mandarin Chinese, the $X+b i($ 比 $)+N+$ hai $($ 还 $)+N$ construction is widely used both in daily communication and in literary and artistic works. For example,

（5）月嫂工资比白领还白领，大学生辞职当月嫂。(《理财咨询》)

'To be a confinement lady can earn better than a white-collar employee, thus many graduate students take the profession of a confinement lady as their job.'

The noun 白领 after hai (还) is decategorized in this construction. Syntactically, it cannot be preceded by any determiners or adjectives. It is placed after the adverb hai (还) where a predicate should occur and gain the characteristics of an adjective. Semantically, it is used here to emphasize certain distinguishable features of itself, namely, its high income.

\section{Adverbalization of Nouns}

In daily communication, some nouns in Mandarin Chinese can also play an adverbial function in order to achieve expressive effects under certain conditions. For example,

(6) 我现在太忙了, 回头手机联系吧。

'I am busy now; I will connect you on mobile phone.'

In (6), 手机 is decategorized when followed by a verb. It loses morphological features of a noun, functioning as an adverb and denoting the manner of action of the following verb.

\section{Verbalization of Nouns}

Verbalization of nouns refers to the language phenomenon of which a noun is transformed into verbs under certain conditions for a temporary use. For example,

(7) a. 他猫在家里不敢出门

'He stays at home and do not dare to go out.'

b.昨天我美团了一张电影票。

'Yesterday, I bought a ticket on the Meituan.com.'

In (7b), 美团 means to buy on Mei Tuan. com. In (7a), 猫 means the manner of staying at home just like a sleeping cat. Both nouns are decategorized, denoting a kind of action.

\section{Metonymy-Metaphor InTERACTION AS the Basic Working Mechanism of DeCATEGORIZATION OF Nouns in MANDARIN CHINESE}

After analyzing data we collected, the basic working mechanism of decategorization of nouns in Mandarin Chinese is metonymy-metaphor interaction. More specifically, it is the metaphor from metonymy that works in all the three types of decategorization of nouns, with metonymy functioning at the initial stage and metaphor at the final stage of decategorization.

Metonymy as the Working Mechanism at the First Stage

The encyclopedic nature and duality of a concept as well makes it possible for metonymy occur in the working mechanism of decatogarization of nouns in Mandarin Chinese.

\section{Semantic Prerequisites for Metonymical Mechanism}

As is defined, metonymy is a relationship between the source domain and the target domain of which the target domain can be grasped through the mental bridge provided by the source domain. Here a question is asked: What makes it possible for this mechanism to work in decategorization of nouns in Mandarin Chinese? What are the semantic prerequisites? The answer to the question can be provided by cognitive view of meaning, especially Jackendoff's theory of duality of concept.

According to cognitive linguistics, natural language is the production of human mind and the meaning of language 
should be studied from the perspective of human cognition. That means the meaning of a lexical item is not just about its reference in the real world but is based on the concept formed out of experience of that entity. That is to say, meaning is not objective and isolated but is related to knowledge stored in our mind. Evans and Green (2006) make four basic assumptions about cognitive semantics, in which he insists that meaning representation is encyclopedic. Taylor (1995) holds the idea that cognitive linguistics treats meanings as context dependent, which means the meaning can be explained with connection to its related things instead of in isolation.

So meaning can only be fully described according to the encyclopedic knowledge of a concept. The encyclopedic nature of meaning is best illustrated by the theory of duality of concept proposed by Jackendoff (1983).

In order to study the relationship between semantics and cognition, Jackendoff (1983) distinguishes two types of notions of a concept: token and type. The token notion concerns the internal structure of a concept, which is a mental construct with a potentially elaborate internal structure that can be mapped onto the human mind as a unified entity. The token notion is a representation of the categorized entity.

The type notion refers to the representation of the category, which includes the information and knowledge that people have created and stored in their mind in the process of acquiring the category. The type notion is a mental construct without referring meaning, namely what is stored in this notion does not have any specific referent in this category or in the real world. In a word, type notion of an entity refers to the encyclopedia knowledge about the concept. For example, the token notion of 白菜 (Chinese cabbage) refers to a round vegetable with large green, purplish-red or white leaves that can be eaten raw or cooked. However, the type notion of 白菜 not only embraces the information above but also includes the associated information and knowledge people have stored in the process of acquiring that word in Chinese culture, for example, the lowness of its price and being affordable by common families. This kind of associated meaning is of high degree of conventionalization.

The difference between token and type notion is a reflection of the conversion between referring and assertion in language. The two notions of concept are also different in terms of stability. Since the type notion is made up of associated meanings, the content of a type notion is unstable. It varies with time, place and people. Also the density of information in the type notion will be changed with the development of language. It may become denser due to the high frequency use of certain words, which means new information will be added to the type notion of a word. On the contrary, density may become lower because of the less frequency of use. As a result, the differences between token notion and type notion also reflect the flexibility of conceptual content of linguistic entities. The token notion shows the stable aspect of the category structure while type notion reveals the creative and dynamic aspects of that structure.

The duality of concept, especially the dynamic nature of the type notion of an entity, makes metonymical mapping possible, thus providing semantic prerequisites for decategorization of nouns in Mandarin Chinese.

\section{WHOLE-PART METONYMY as the Working Mechanism}

Sorting out the language data collected, we found that the working mechanism for decategorization of nouns in Mandarin Chinese at the first stage is WHOLE-PART METONYMY.

As has been stated above, according to Jackendoff's theory of duality of concept, the meaning of a typical noun is mainly made of two parts, namely, the token notion and the type notion. In this paper, the token notion of a concept is referred to as the token notion domain and the type notion as the type domain. The type notion domain is also divided into many sub-domains as it includes many meaning components.

When typical nouns are used, only the token notion domain is activated, which can be showed in Figure 3.

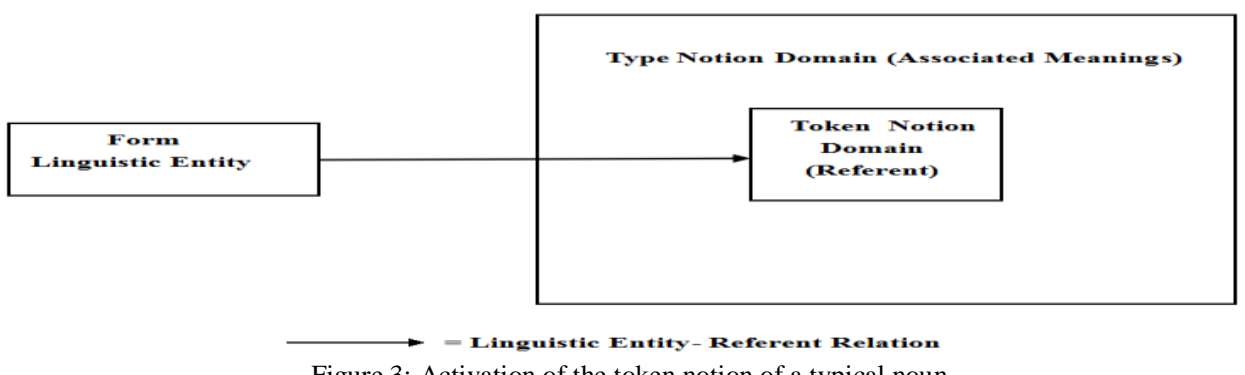

Figure 3: Activation of the token notion of a typical noun

Figure 3 indicates that for some typical nouns, only the token notion is conceptually salient without concerning its type notion. The token notion is basic and the type notion is acquired based on the token notion. Also the token notion concerns the linguistic entity and referent relation.

However, when nouns are decategorized, nouns do not refer to their referents any more. In such a process, the token notion functions as the vehicle entity and gives mental access to its type notion. As a result, the type notion domain which consists of many sub-domains is activated. This process is also referred to as meaning elaboration. Then based on the concrete contexts, the type notion domain is reduced and a certain sub-domain is highlighted. And in this way, the intended meaning is grasped. This process can be showed in Figure 4. 


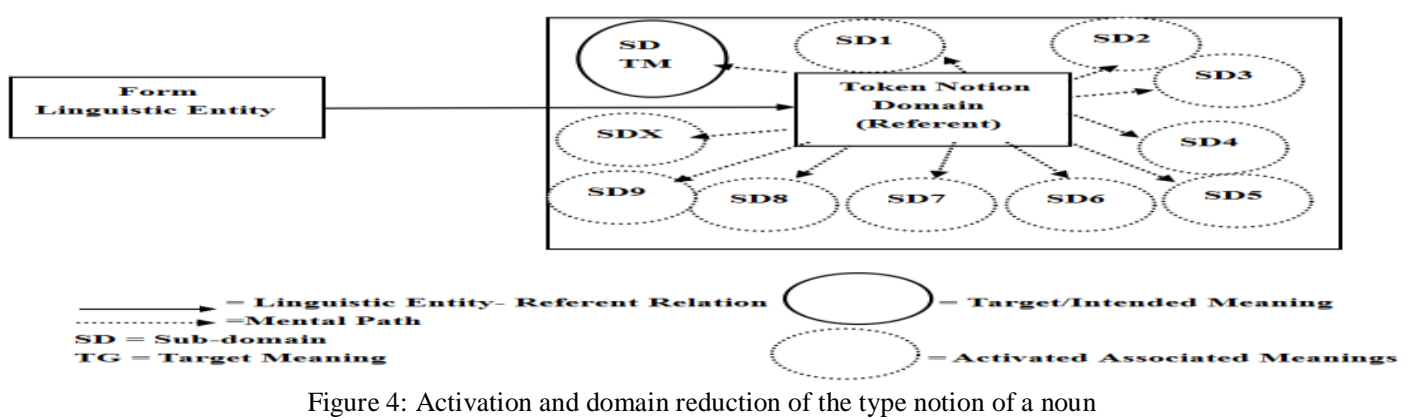

So at the initial stage of decategorizaiton of nouns in Mandarin Chinese, the working mechanism here is WHOLE-PART METONYMY, in which the type notion domain is used to refer to its sub-domain. More specifically, if we treat the noun as a cognitive domain and the meaning of a noun as its features, it belongs to the DOMAIN-FEATURE METONYMY. Let us look at some examples.

(8) a. 那个商人是他父亲。

'That businessman is his father.'

b. 商人就是商人。

'Businessmen are businessmen.'

According to what we have discussed above, the meaning of 商人 can be understood in terms of its token notion domain or type notion domain. In (8a), the linguistic form 商人 refers to its token notion domain, a real man in communication without relating to its associated meanings.

In (8b), 商人 especially the second one is decategorized. The associated meanings of 商人 will be activated unconsciously by its token notion. For example, some successful businessmen are very rich, smart and hardworking. Also some businessmen are associated with profiteers who are very mean and place money over everything, etc. Then the intended meaning is caught through the WHOLE-PART METONYMY. In different contexts, different sub-domains in the type notion domain of 商人 will be highlighted.

WHOLE-PART METONYMY is the working mechanism for all the decategorized nouns in the examples of the previous sections.

In the second type of $N 1+N 2$ construction, the meaning $N 1$ is derived by WHOLE-PART METONYMY, in which one meaning element in its type notion of $N 1$ is expressed. In (2h), 银 refers to its color; in (2d), 斑马 denotes the stripes on the body of the zebra; in (2c), 铁 suggests the tough personality; in (2b) 土豪 refers to the luxuriousness of the color; in (2f). 水桶 reveals the shape of one's waist.

In (6), 手机 means the way of connecting others by using the mobile phone and functions as an adverb and refers to the manner of the action. This kind of associated meaning which can be treated as a feature of 手机 is obtained from the type notion domain. From the micro perspective, it is PRODUCT-FUNCTION METONYMY, a type of WHOLE-PART METONYMY.

\section{Mode of Metonymical Mapping}

As has been stated above, WHOLE-PART METONYMY concerns the process of meaning elaboration and the reduction of the domain. As a result, certain sub-domains of its type notion domain or the intended meanings will be understood accordingly. So a question arises at this point, how is the proper meaning chosen in this kind of metonymy?

According to Liu (2006), the intended meaning is obtained through metonymical perspectivization. Also, in certain contexts, speaker's attitude can be reflected while choosing the intended meaning.

Perspectivization is a mechanism which can highlight different components of frame-based knowledge whose semantic structure is rather complex (Taylor, 1995). So metonymical perspectivization is a very important component of metonymy, by which a certain characteristic of a concept can be selected. In many situations, the perspectivization of a certain constituent in the semantic frame is grounded by other constitutes. Sometimes, it might entirely suppress them. It is the major means for semantic extension and reification.

Metonymical perspectivization is made up of two aspects, namely, perspectivization of constituents and perspectivization of meaning.

Perspectivization of constituent refers to the highlighting of certain semantic constituents while neglecting others in a certain context.

（9）她的外表很城市，性格却很乡村。（《小说月报》, 2002）

'She has a good appearance and simple personality.'

In (9), 城市 and 乡村 are two decategorized nouns in the Adverb+Noun construction, expressing a kind of assertive meaning. The type notion of 城市 includes many associated meanings, such as modernization, civilization, prosperity, etc. And the type notion of 乡村 has meanings such as simplicity, conservativeness, ignorance, poverty, etc. All these associated meaning components can be activated unconsciously; however, not all these meaning constituents can be highlighted. According to the context it occurs, the good looking and fashion of people living in cities and simple 
characters about people in rural areas are highlighted while others associated meanings are neglected.

Actually different components in the type notion domain will be highlighted according to different contexts through metonymical perspectivation. For example,

(10) a. 那位男老师的讲课风格太女人了。

'That male teacher's teaching style is the same as the female teacher's.'

b. 当断则断, 不要那么女人好吗。

'Try to make a decision in time, don't be so indecisive.'

In (10), different associative meaning components of 女人 is highlighted. In (10a), the feature of a woman with small strength and low voice is highlighted and used to describe a male teacher. And in (10b), the indecisive nature of some women is highlighted.

Perspectivization of meaning refers to the creation of additional meaning under certain conditions especially the subjective meaning of a speaker or writer. The speaker's subjective meaning or attitude can be expressed through a new way by the language itself, out of the consideration of politeness, acceptability and relevance, etc (Traugott $\&$ Dasher, 2002). This process is also called subjectivization. And in different contexts, the same noun can be decategorized to denote different attitudes of the speaker through the perspectivization of meaning.

(11) a. 我们的关系很铁。

'We have a close relationship.'

b. 他是铁心当叛徒了。

'He made a firm decision to be a traitor.'

The type notion domain of 铁 includes many aspects. The hardness nature of iron is selected and mapped to describe the relationship of two people in (11a) and one's determination in (11b). In (11a) and (11b), the meaning of 铁 is captured through metonymical perspectivation of constituent. However, in (11a) a kind of positive attitude is conveyed while in (11 b) a kind of criticism is revealed.

In summary, at the initial stage of decategorization of nouns, the mechanism is WHOLE-PART METONYMY. More specifically, it is DOMAIN-FEATURE METONYMY. The intended meaning is derived by the reduction of the rich information in the source domain according to the context. This is done through metonymical perspectivization.

\section{Metaphor as the Working Mechanism at the Final Stage}

Metonymy operating at the initial stage of decategorization of nouns in mandarin Chinese conceptually motivates metaphor to work, enabling a concrete noun to express an abstract meaning. In such a process, there involve both categorical and conceptual metaphors, with the former as the majority.

\section{Categorical Metaphor as the Working Mechanism at the Final Stage}

DOMAIN-FEATURE METONYMY provides basic working mechanism for understanding decategorized nouns in Mandarin Chinese. With this mechanism at work, we are able to use a concrete noun to express an abstract idea. Thus, decategorization of nouns enters the second stage and the working mechanism is metaphor.

According to our language data, in most cases, categorical metaphor works at the final stage of decategorization of nouns in Mandarin Chinese, in which concrete objects are used to refer to abstract notions. We found that some typical nouns referring to person, object or activity are often the source domains, while some abstract notions such as those referring to characteristics, space or time are often the target domains.

Let us look at some examples given in the previous sections again. The nouns, such as 斑马 in (2d), 战士 in (4), 手机 in (6), 水桶 in (2f) and 猫 in (7a) all undergo metaphorical process in which the concrete nouns are used to express an abstract meaning.

斑马 in (2d) is an OBJECT used to describe the shape of the crossing. The source domain is 斑马 while the target domain is the kind of crossing we would like to describe. Thus it belongs to OBJECT-TO-QUALITY METAPHOR. The same type of metaphor can be found in (2f). Being the source domain, 水桶 is used to describe the target domain, the shape of one's waist. In (4), 战士 is a PERSON used to refer to characteristics of a fighter and it belongs to PERSON-TO-QUALITY METAPHOR. In(7a), 猫 is an animal and is used to denote a person who likes staying at home without going outside. Thus it belongs to OBJECT-TO-QUALITY or ANIMAL-TO-QUALITY METAPHOR.

In (11b), the meaning of the second 商人 is derived with the reduction of the type notion according to the context by the WHOLE-PART METONYMY. This process enables the concrete noun to emphasize an abstract notion in the type notion domain of 商人. Thus it is a PEOPLE-TO-QUALITY METAPHOR.

Conceptual Metaphor as the Working Mechanism at the Final Stage

As is shown above, in most cases, categorical metaphor works in decategorization of nouns. However, our data indicate that there are also cases in which conceptual metaphor functions, but much less in number than categorical metaphor.

By conceptual metaphors, the meaning of a typical noun is extended and becomes abstract. For example,

(12) 一个蛇瓶

'A snake vase'

In (12), 蛇瓶 can be understood in two ways. The first refers to a vase used to hold snakes and the second to a 
specific vase with carved snake on it.

For the first meaning, the word 蛇 cannot refer to any specific snake any more, thus it undergoes generalizing or abstracting and belongs to the categorical metaphor. While, the second understanding is the conceptual metaphor, as 蛇 refers to the carved object which looks like a snake. Thus, this metaphorical extension happens while its categorical status does not change completely.

\section{CONCLUSION}

From the discussion above, we can draw the following conclusion:

The working mechanism of decategorization of nouns in Mandarin Chinese is metonymy-metaphor interaction, mainly metaphor from metonymy, with metonymy working at the initial stage and metaphor at the final stage.

The metonymy belongs to the WHOLE-PART type, with the type notion of a noun as the source domain (WHOLE) and the meaning components in source domain as the target domain (PARTS). It concerns meaning elaboration and reduction of the source domain. By this mechanism, certain meaning components in the source domain are highlighted and chosen through metonymical constituent perspectivization and subjectivization in a context. This enables a noun to express expressive or assertive rather than referent meaning.

Motivated by the WHOLE-PART METONYMY at the first stage, decategorization enters the final stage, of which the working mechanism is mainly categorical metaphor, with conceptual metaphor as a complement.

\section{REFERENCES}

[1] Barcelona, A. (2000). Metonymy and metaphor at the crossroads: A cognitive perspective. Berlin: Mouton de Gruyter.

[2] Berlin, B., \& Kay, P. (1969). Basic color terms: Their universality and evolution. Berkeley: University of California Press.

[3] Croft, W. (1993). The role of domains in the interpretation of metaphors and metonymies. Cognitive Linguistics, 4(4), 335-370.

[4] Evans, V., \& Green, M. (2006). Cognitive linguistics: An introduction. Edinburgh: Edinburgh University Press.

[5] Goossens, L., P. Pauwels, B. Rudzka-Ostyn, A. M. Simon-Vandenbergen, \& Vanparys, J. (1995). By word of mouth: Metaphor, metonymy and linguistic action in a cognitive perspective (Vol. 33). Amsterdam: John Benjamins Publishing Company.

[6] Heine, B., Claudi U., \& Hünnemeyer F. (1991). Grammaticalization: A conceptual framework. Chicago: Chicago University Press.

[7] Hopper, P. J., \& Thompson S. A. (1984). The discourse basis for lexical categories in universal grammar. Language, 60, 703-752.

[8] Jackendoff, R. S. (1983). Semantics and cognition (Vol. 8). Cambridge: MIT press.

[9] Lakoff, G. (1987). Women, fire and dangerous things. Chicago: University of Chicago Press.

[10] Lakoff, G., \& Johnson, M. (1980). Metaphors we live by. Chicago: University of Chicago Press.

[11] Langacker, R. W. (1993). Reference-point construction. Cognitive Linguistics, 4, 1-38.

[12] Liu Runqing \& Liu Zhengguang. (2004). Characteristics of Noun Decategorization. Language Teaching and Linguistic Studies:03:1-13.

[13] Liu Runqing \& Liu Zhengguang. (2005). The Significance of Theory of Linguistic Decategorization. Foreign Language Teaching and Research: 01:29-36.

[14] Liu Zhengguang. (2005). The Working Mechanism of Linguistic Decategorization. Foreign Languages Research:01:9-15.

[15] Liu Zhengguang. (2006). Linguistic Decategorization: An Integral Part of Linguistic Categorization. Shanghai: Shanghai Foreign Language Education Press.

[16] Liu Zhengguang \& Cui Gang. (2005). Decategorization and the Adv+N construction. Foreign Languages: 02: 37-44.

[17] Pan Zhen. (2010). Metonymy in the Categorization of Metaphoric N+N compounds. Modern Foreign Languages: 04: $371-378$.

[18] Panther, K-U \& Thornburg, L. (1998). A cognitive approach to inferencing in conversation. Journal of Pragmatics, 30: 755-769.

[19] Peng Yuehua \& Liu Zhengguang. (2007). Some Issues in the N-V Study. Foreign Language Research.06: 40-45.

[20] Radden, G., \& Kövecses, Z. (1999). Towards a theory of metonymy. In K-U Panther \& G. Radden (Ed.), Metonymy in language and thought (pp. 17-60). Amsterdam: John Benjamins.

[21] Rosch, E. (1978). Principles of Categorization. In E. Rosch \& B. B. Lloyd (eds.), Cognition and categorization (27-48). Hillsdale, New York, N. Y: Lawrence Erlbaum.

[22] Ruiz de Mendoza, F. (2000). The role of mappings and domains in understanding metonymy. In A. Barcelona (eds.), Metaphor and metonymy at the crossroads: A cognitive perspective (109-132). Berlin: Mouton de Gruyter,.

[23] Taylor, J. R. (1995). Linguistic categorization: Prototype in linguistic theory. Oxford: Oxford University Press.

[24] Traugott, E. C., \& Dasher, R. B. (2002). Regularity in semantic change (Vol. 97), Cambridge: Cambridge University Press.

[25] Wittgenstein, L. (1953). Philosophical investigations. Oxford: Blackwell Publishing.

Zhen Li was born in Tengzhou, Shandong Province, China in 1988. He has a Bachelor degree in English in 2012, a MA in General Linguistics from Beijing Language and Culture University. He teaches courses including College English and Integrated English for English Majors. His research areas of interest include Cognitive Linguistics and Second Language Acquisition. 